\title{
DIFFERENT ASPECTS OF SOFT COMPUTING METHODS APPLICATION FOR BLASTING IN MINING
}

\author{
Katarina Urošević ${ }^{1}$, Jelena Zakonović ${ }^{2}$, Jelena Ignjatović ${ }^{1}$, Radmila Gaćina ${ }^{1}$
}

Received: December 6, 2019

Accepted: December 25, 2019

\begin{abstract}
Mining is a global industry that is of great importance for every product which is used by human. For mining, process efficiency, reducing production downtime, increasing profitability are all very important. Soft computing technologies (SC) are helping in the process of transforming the mining industry into a safer and more environmental friendly industry, but keeping in mind the financial aspect as well. In this paper some of fields of blasting activities in which the SC methods have been applicated, will be presented. Trough the following chapters some of the most significant researches will be reviewed.
\end{abstract}

Keywords: soft computing; blasting; fuzzy logic; neural networks;

\section{INTRODUCTION}

We are witnessing of SC becoming a powerful tool for analyzing data of all kinds in the mining industry. In this paper there will be shown several researches that have used some of the SC to overcome difficulties in rock blasting. The ability of these methods to consider uncertainty and to deal with lack of informations, has provided them possibility to be applied in some complex problems in exploitation of mineral raw materials. SC is used to increase the efficiency, effectiveness, environmental and safety concerns.

Of all mining activities, blasting is one of the most important. That importance comes from its role in exploitation of mineral raw materials and that is to break rock by using explosives. In this way it is provided a specific fragmentation and distribution of rocks. Drilling and blasting operations are still considered as the most economical method to break a rock mass of all existing methods for that purpose in mining activities.

Properly organized and executed operations related to the drilling and blasting process increase the efficiency and reduce production costs of drilling and mining operations, which with about $25 \%$ to $40 \%$ affect the overall production costs of the mine (Purtić, 1991).

\footnotetext{
${ }^{1}$ University of Belgrade - Faculty of Mining and Geology

${ }^{2}$ Metalfer, d.o.o. Bulevar Mihajla Pupina 115 A 11000 Belgrade, Serbia Emails:katarina.urosevic@ rgf.bg.ac.rs;jelena.zakonovic@ metalfer.net;jelena.ignjatovic@ @rg f.rs;radmila.gacina@rgf.rs
} 
Determination of blasting parameters is not an easy task, there are many factors that must be considered that affect the success of these operations. The behavior of a rock massif when is exposed to drilling and blasting operations depends on many factors, for that reason the rock blasting is characterized as uncertain activity.

\section{SOFT COMPUTING METHODS APPLICATED FOR BLASTING}

Soft computing is defined as: "a collection of methodologies that aim to exploit the tolerance for imprecision and uncertainty to achieve tractahility, robustness, and low solution cost", (Zadeh, 1994).

Methods of soft computing field are one innovative approach to create an intelligent system for dealing with some problems or to make a decision support system. Knowing that problem solving requires a multidisciplinary approach that includes knowledge, techniques and methodology of different origins engineers in mining industry had started to applicate SC methods in order to create system that works like human mind, approximately.

SC methods that are the most used are Fuzzy logic (FL), Artificial neural networks (ANN) and Evolutionary algorithms (EA). The first study of artificial intelligence comes in 1943. and as its creators are considered McCulloch and Pitts (Mcculloch and Pitts, 1943). They have introduced an initial model of artificial neural network and till nowadays we have a significant number of researches related to this field.

In his article "Fuzzy Sets", Zadeh (1965), defines the concept of Fuzzy logic first time. Apart from these, are also widespread hybrid algorithms that combine different types of mathematic methods. Because of imprecision of SC methods, their implementation is limited to areas where its imprecision is acceptable. In order to solve this problem of implementation, adequate mathematical tools have begun to be used, which can be transformed or optimized for practical use. Scientific application of these methods and hybrid systems will be presented in following review.

\subsection{Different aspects of SC application for blasting problems}

Depending on the tasks that needs to be fulfilled there are different blasting designs. Especially, due this activity in mining it is necessary to take care about safety of people and environment. Due to the existence of different blasting designs and the consequences of blasting, Soft computing technologies have found their application in this field. Detailed analysis of blasting and blasting related tasks can be found in books of Savić (2000) and Purtić (1991).

Systems powered by SC use different algorithms to organize and understand the vast amount of data in order to create optimal decisions. 
In this paper are shown some of the representative examples of utilization of SC methods for different blasting problems. In figure 1 are shown the most common blasting related aspects for which soft computing technologies are used in researching and shown in this review.

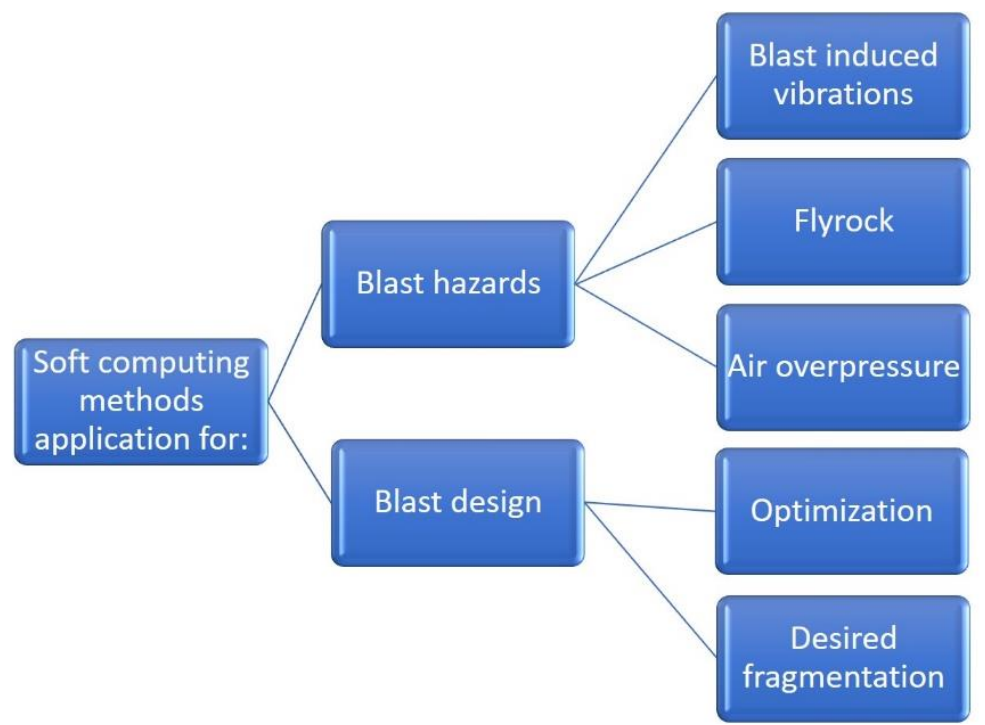

Figure 1 The most common blasting related aspects for which soft computing technologies are used in researches

Blasting activities inevitably affect the environment and cause discomfort to the surrounding population and environment in general. To avoid danger of this negative consequences scientist started using SC methods. One of negative effects are ground vibrations induced by blasting.

From earlier research related to application of SC methods to predict ground vibrations caused by blasting it is important to mention Chakraborty et al. (2004) who presented a new approach for prediction blasting caused vibrations. First, it is tested the effectiveness of multilayer perceptron networks (MLP), then adopted on-line feature selection method and a fusion network which uses several MLPs to realize an improved prediction system. This study has shown that use of fusion networks was better than empirical prediction models.

Second important article brought Iphar et al. (2008), in their research they have compared a regression model and fuzzy based model for prediction of the peak particle velocity (PPV). The study is based on 44 measurements. This research was attempt has to explore the applicability of SC method called as the adaptive neuro-fuzzy inference system (ANFIS) to predict PPV. The data collected from measurements are evaluated by composing an ANFIS prediction model. As input parameters for this model the authors took distance of monitoring stations to blasting site and explosive charge weight per 
delay and the output was PPV. As a result, it has shown that even though the prediction of the regression model was high, the proposed ANFIS model gave better prediction. ANFIS model has correlation between measured and predicted values as 0,99 and in regression model as 0,9 .

Some other studies tried to predict ground vibrations caused by blasting using SC technologies. Emphasizing the importance for restricting the environmental effects of blasting activities Fisne et al. (2011) made an effort to predict PPV using FL and classical regression analysis. One other prediction of PPV and frequency was made by ÁlvarezVigil et al. (2012). They used information about physical and mechanical properties of rock mass and explosive and design of blasting and implemented in ANN model. Hajihassani et al. (2015) attempted to make an hybrid model of ANN and imperialist competitive algorithm for prediction of PPV in granite quarry site.

The other one negative effect of blasting is fly rock. That negative effect represents the rock propelled beyond the blast area by the power of an explosion. With aim to avoid the consequences of fly rock, it is necessary to define safety distances in order to take certain measures within the area to protect both employees and objects in the environment. SC technologies have found their place in this problem, there are many researches about this issue. Monjezi et al. (2012) attempted to develop a neuro-genetic model for predicting fly rock and backbreak in one copper mine. To optimize neural network parameters like number of neurons in hidden layer, learning rate, and momentum the authors of this paper used genetic algorithm. The output of a new model was examined by statistical method and that shown that efficiency of model is on highest level.

An effort to applicate fuzzy logic at this consequence of blasting was made by Rezaei et al. (2011). They used fuzzy model based on Mamdani inference system to predict fly rock due blasting in an iron mine. One database of 450 data was made, the input parameters of model were: burden, spacing, hole depth, specific drilling, stemming length, charge per delay, rock density and powder factor and output was fly rock. Every parameter had his Min and Max value determinated in model. At the end the authors made a comparation of results with statistical methods and that analysis has shown superiority of the developed fuzzy model.

Several others scientist employed SC methods to predict fly rock, such as Marto et al. (2014), who used imperialist competitive algorithm in combination with ANN, or Ghasemi et al. (2012) who used ANN and FL model for prediction and made comparation of result of both models.

Sawmliana et al. (2007) built an ANN model for prediction of air overpressure from blasting. For that purpose, they used parameters like maximum charge weight per delay, total charge initiated in a round and distance of measurement. ANN in combination with 
FL, or above mentioned ANFIS model, for prediction of air overpressure induced by blasting, also used Armaghani et al. (2015).

Besides of negative effects induced by blasting, several researches also tried an optimization of blast design with SC methods. Monjezi et al. (2011) employed ANN and Genetic Algorithm to optimize blasting parameters for one copper mine. A rock fragmentation also may be predicted with SC technologies, that demonstrated Kulatilake et al. (2010). The content of their database are blast design parameters, explosive parameters, modulus of elasticity and in-situ block size and that parameters were used in ANN model for prediction of rock fragmentation.

\section{CONCLUSION}

SC support better and faster decision making, especially in mining processes. Inevitable impact on the environment and reason of making discomfort to the surrounding population are blasting activities. To avoid danger of this negative consequences, scientist started using SC methods.

In this paper are presented some examples how SC methods can be applicated in blasting and what is their contribution to these activities. Some of the most important methods are mentioned and some of the most significant articles are reviewed.

In order to effectively applicate SC technologies in blasting activities, adequate mathematical tools are used, in purpose of transformation or optimization of this methods for practical use.

Many studies have employed FL or ANN to predict some of important blasting effects. The other ones combined AL and ANN such as neuro-fuzzy algorithms or used GA as well. Most of the studies used some statistical methods for verification of applicated new model and in every study new model seem to be more precise than classical methods for prediction.

SC are important for these activities because they can help to reduce and sometimes to prevent the hazardous blasting impact on the environment. Application of these technologies may lead to increasing the organization's capacity to accomplish tasks, make decisions and generate stronger business outcomes. SC techniques are still developing and their application to many areas in mining process will increase massively in future.

\section{Acknowledgment}

The authors thank the Serbian Ministry of Education, Science and Technological Development for their support on the Project of Technological Development TR33003. 


\section{REFERENCES}

ÁLVAREZ-VIGIL, A.E. et al. (2012) Predicting blasting propagation velocity and vibration frequency using artificial neural networks. International Journal of Rock Mechanics and Mining Sciences, 55, pp. 108-116.

ARMAGHANI, D.J. et al. (2015) Neuro-fuzzy technique to predict air-overpressure induced by blasting. Arabian Journal of Geosciences, 8 (12), pp. 10937-10950.

CHAKRABORTY, A. et al. (2004) A fusion Neural Network for estimation of blasting vibration. In: Neural Information Processing. ICONIP 2004. Lecture Notes in Computer Science, Berlin, Heidelberg: Springer pp. 1008-1013.

FIŞNE, A. KUZU, C. and HÜDAVERDI, T. (2011) Prediction of environmental impacts of quarry blasting operation using fuzzy logic. Environmental Monitoring and Assessment, 174 (1-4), pp. 461-470.

GHASEMI, E. et al. (2012) Application of artificial intelligence techniques for predicting the flyrock distance caused by blasting operation, Arabian Journal of Geosciences, 7 (1), pp. 193-202.

HAJIHASSANI, M. et al. (2015) Ground vibration prediction in quarry blasting through an artificial neural network optimized by imperialist competitive algorithm. Bulletin of Engineering Geology and the Environment, 74 (3), pp. 873-886.

IPHAR, M., YAVUZ, M., and AK, H. (2008) Prediction of ground vibrations resulting from the blasting operations in an open-pit mine by adaptive neuro-fuzzy inference system. Environmental Geology, 56 (1), pp. 97-107.

KULATILAKE, P. et al. (2010) Mean particle size predictionin rock blast fragmentation using neural networks. Engineering Geology, 114 (3-4), pp. 298-311.

MARTO, A. et al. (2014) A Novel Approach for Blast-Induced Flyrock Prediction Based on Imperialist Competitive Algorithm and Artificial Neural Network. The Scientific World Journal, 2014, Article ID 643715, 11 pages. [Online] Available from: http://downloads.hindawi.com/journals/tswj/2014/643715.pdf [Accessed 20/11/2019]

McCULLOCH, W.S. and PITTS, W. (1943) A logical calculus of the ideas immanent in nervousactivity. The bulletin of mathematical biophysics, 5 (4), pp. 115-133.

MONJEZI, M., AMINI KHOSHALAN, H. and YAZDIAN VARJANI, A. (2012) Prediction of flyrock and backbreak in open pit blasting operation: a neuro-genetic approach. Arabian Journal of Geosciences, 5 (3), pp. 441-448.

MONJEZI, M. AMINI KHOSHALAN, H. and YAZDIAN VARJANI, A. (2011) Optimization of Open pit Blast Parameters using Genetic Algorithm. International Journal of Rock Mechanics and Mining Sciences, 48 (5), pp. 864-869. 
MONJEZI, M. et al. (2014) Application of soft computing in predicting rock fragmentation to reduce environmental blasting side effects. Arabian Journal of Geosciences, 7 (2), pp. 505-511.

PURTIĆ, N. (1991) Bušenje i miniranje. Belgrade: Faculty of Mining and Geology.

REZAEI, M., MONJEZI, M. and YAZDIAN VARJANI, A. (2011) Development of a fuzzy model to predict flyrock in surface mining. Safety Science, 49 (2), pp. 298-305.

SAVIĆ, M. (2000) Miniranje na površinskim kopovima. Bor: Institute for Copper.

SAWMLIANA, C. et al. (2007) Blast induced air overpressure and its prediction using artificial neural network. Transactions of the Institution of Mining and Metallurgy, Section A: Mining Technology, 116 (2) pp. 41-48.

ZADEH, L.A. (1994) Soft computing and fuzzy logic. IEEE Software, 11 (6), pp. 48-56.

ZADEH, L.A. (1965) Fuzzy sets. Information and Control, 8(3), pp. 338-353. 